Ann. Biol. anim. Bioch. Biophys., I975, 15 (I), II5-II8.

NOTE

\title{
APPORT DE PROTÉINES D'ORIGINE ENDOGENE PAR LA SÉCRÉTION DU PANCRÉAS EXOCRINE CHEZ LE PORC
}

\author{
T. CORRING \\ avec la collaboration technique de Anne-Marie GuevgneaU \\ Laboratoire de Physiologie de la Nutrition, \\ Centre national de Recherches zootechniques, I. N.R.A., \\ 78350 Jouy en Josas
}

\section{RÉSUMÉ}

Une étude portant sur 7 porcs de poids vif moyen de $45 \mathrm{~kg}$ environ montre que la sécrétion pancréatique excréte $18,6 \mathrm{~g} \pm 0,6$ (86 données) de protéines endogènes, par 24 heures. Cet apport constitue environ I I p. roo de l'azote ingéré et les acides aminés présents dans le suc pancréatique représentent 5 à $8 \mathrm{p}$. Ioo des besoins quotidiens du porc en croissance.

\section{INTRODUCTION}

Dans la plupart des revues consacrées à l'étude de la digestion et de l'absorption des protéines chez le monogastrique, est posé le problème de l'importance et de la signification nutritionnelle de l'azote ingéré. Nasset et Ju (I96I), Twombly et Meyer (I96I) montrent que chez le Chien et le Rat, la proportion d'azote endogène est très supérieure ( 7 à 9 fois) à celle d'azote exogène résiduel, après le repas. A l'opposé, Nixon et MAWEr (1970) mettent en évidence, chez l'Homme, que l'azote endogène ne représente que la moitié de l'azote ingéré. De même, selon ZkBrowska (I973), la composition en acides aminés totaux ou libres des contenus duodénaux du porc est très influencée par le régime.

Comme le souligne SNook (1973), la méthodologie employée doit être à l'origine de ces divergences. De plus, les estimations des différents apports endogènes sont aussi probablement une source importante de variation. Ces estimations varient de I à 6 , selon les hypothèses utilisées 
pour effectuer les calculs mais il faut préciser que la plupart des auteurs optent pour des quantités relativement faibles: $70 \mathrm{~g}(\mathrm{~N} \times 6,25)$ pour un homme de $70 \mathrm{~kg}$ (MunRo, 1966), $40 \mathrm{~g}(\mathrm{~N} \times 6,25)$ environ pour un porc de $50 \mathrm{~kg}$ (ZeBrowsKa et BuracZewsKa, 1972).

Les sécrétions digestives représentent une partie non négligeable de l'apport endogène total et certaines d'entre elles peuvent être aisément récoltées quantitativement et leur apport azoté déterminé.

Nous nous proposons de rapporter ici un nombre relativement important de données sur l'apport spécifique de la sécrétion pancréatique exocrine chez le Porc.

\section{MÉTHODOLOGIE}

7 porcs mâles castrés, de race Large White, et de poids vif moyen en cours d'expérimentation d'environ $45 \mathrm{~kg}$, ont été munis de fistule pancréatique et duodénale (CorRING et al., 1972).

Le suc pancréatique est recueilli en permanence, mesuré et échantillonné sur 24 heures pour la détermination des protéines totales selon la technique de LowRY et al., (I95I). Il est réintroduit en continu par le cathéter duodénal, à l'aide d'une pompe péristaltique à débit variable (Varioperpex, LKB) à raison de $200 \mathrm{ml} / \mathrm{h}$ sur les 4 heures qui suivent les repas et à raison de $100 \mathrm{ml} / \mathrm{h}$ en dehors des périodes post-prandiales.

Les animaux sont nourris d'un régime à base de céréales à $16 \mathrm{p}$. Ioo de protéines, auquel ils ont été habitués ro jours avant la mise en place des cathéters. Les mesures ne commencent que 8 à ro jours après I'opération chirurgicale.

\section{RÉSUL'TATS ET DISCUSSION}

Les données sur la quantité totale de protéines excrétées par le suc pancréatique du porc en 24 heures, sont rapportées dans le tableau I.

\section{TABLEAU I}

Protéines totales () excrétées par le suc pancréatique du porc en 24 heurcs

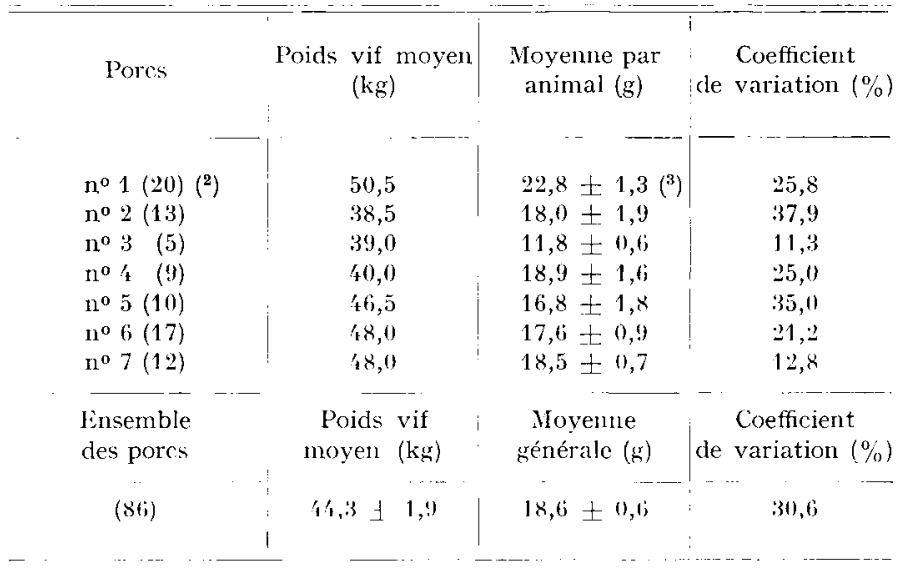

(1) Déterminées selon Lowry et al. (1951).

(2) ( ) : Nombre de donnces.

(3) licart-type à la moyemue. 
La valeur moyenne obtenue à partir des 86 données issues des 7 porcs est de $18,6 \mathrm{~g} \pm 0,6 \mathrm{et}$ elle est très largement supérieure aux 3 à $8 \mathrm{~g}$ trouvés dans le suc pancréatique de l'Homme (LoNG 196I: CRANe, I964). Cette quantité de protéines excrétées par le suc pancréatique se situe par contre dans les limites des 40 à $50 \mathrm{~g}$ d'azote endogène total obtenus par ZeBrowska et BuRACZEWSKa (1972) et par RÉRAT (communication personnelle), selon des techniques différentes.

Dans les conditions expérimentales de cette expérience et pour des porcs ayant consommé en moyenne $\mathrm{I}$ ooo $\mathrm{g}$ d'aliment sec par jour, l'apport endogène pancréatique représente environ II p. Ioo de l'azote ingéré. La composition en acides aminés du suc pancréatique du porc (Corring et JUNG, 1972) permet de chiffrer les quantités d'acides aminés excrétés pendant 24 heures (tabl. 2).

\section{TABLEAU 2}

Quantités d'acides aminés excrétés dans le suc pancréatique du porc en 24 heures

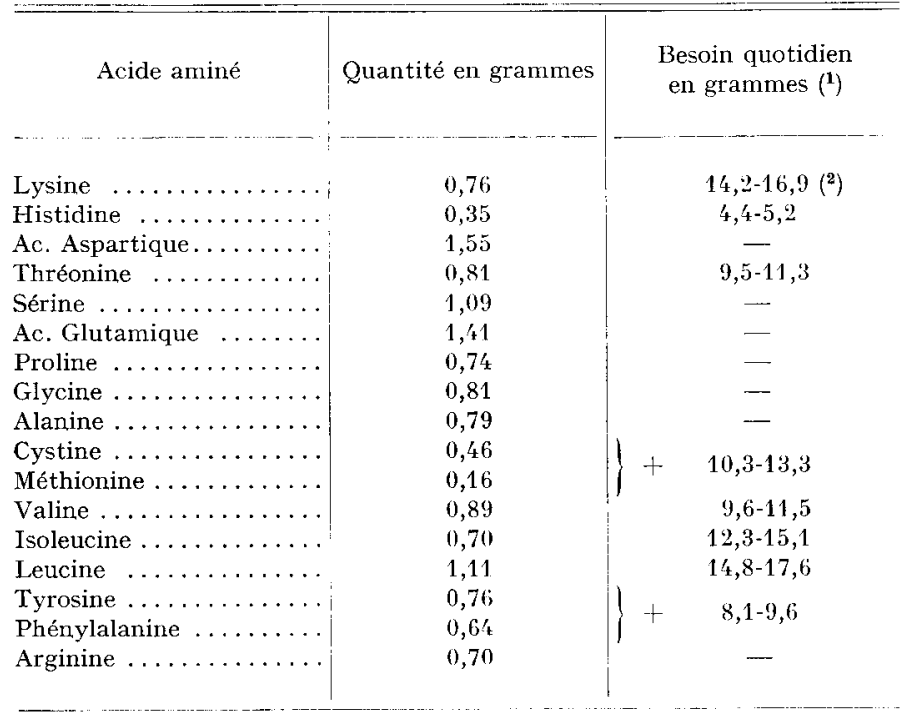

(1) Selon Rérat et Lougnon (1966).

$\left({ }^{2}\right)$ Le 1 er chiffre se rapporte aux besoins pour un poids vif de $40 \mathrm{~kg}$ et le 2 chiffre aux besoins pour un poids vif de $50 \mathrm{~kg}$.

Il apparaît, si l'on considère les besoins quotidiens en acides aminés essentiels de cet animal (RÉRAt et LougNon, I966) que la sécrétion pancréatique peut fournir de 5 à $8 \mathrm{p}$. Ioo de ces besoins. Par ailleurs, l'azote endogène total, si l'on en retient les valeurs de 40 à $50 \mathrm{~g}$, peut fournir de 15 à 25 p. Ioo des acides aminés nécessaires à la croissance du porc. Cependant selon ZebrowsKa et Buraczewska (1972) chez le Porc et Elwyn et al. (r968) chez le Chien, les quantités d'acides aminés dérivés de l'hydrolyse des protéines endogènes doivent égaler les apports d'acides aminés nécessaires pour resynthétiser ces protéines, et ce en état d'équilibre azoté. Tel ne serait plus le cas en périodes de déplétion ou réplétion azotée pendant lesquelles l'intestin devient momentanément fournisseur ou demandeur d'acides aminés (ELWYN, 1970).

En conclusion, il apparaît que la sécrétion pancréatique exocrine chez le Porc représente environ $4^{\circ}$ à 50 p. Ioo de l'azote endogène total. En aucun cas cependant, ces protéines ne peuvent 
constituer un apport nutritionnel quantitatif, en particulier à la suite d'apports exogènes déséquilibrés en acides aminés essentiels, compte tenu notamment de la nécessité d'une resynthèse des protéines enzymatiques du pancréas.

Reçu pour publication en septembre 1974.

\section{SUMMARY \\ ENDOGENOUS PROTEINS EXCRETED IN THE PANCREATIC JUICE OF SWINE}

The endogenous proteins excreted in the pancreatic juice of the pig were determined in 7 fistulated animals of about $45 \mathrm{~kg}$ live weight. The mean value obtained from 86 data is $18,6 \mathrm{~g} \pm 0,6$ per day. This pancreatic supply represents I I p. roo of the ingested nitrogen and the amino acids in the pancreatic juice represent 5 to $8 \mathrm{p}$. Ioo of the daily requirements of the growing pig.

\section{RÉFÉRENCES BIBLIOGRAPHIQUES}

Corring T., Aumaitre A., Rérat A., 1972. Fistulation permanente du pancréas exocrine chez le Porc. Application : réponse de la secrétion pancréatique au repas. Ann. Biol. anim. Bioch. Biophys., 12, $109-124$.

Corring T., Jung J., I972. The amino acid composition of pig pancreatic juice. Nutr. Rep. Intern., 6, I87-I90.

CRANE C. W., I964. Discussion in MunRo H. N. : The role of the gastrointestinal tract in protein metabolism : C. I. O. M. S. Symposium, i I5-II6 (Blackwell Scientific Publications, Oxford, I964).

Elwyn D. H., Parikh H. C., Shoemaker W. C., 1968. Amino acid movements between gut, liver, and periphery in unanesthetized dog. Amer. $J$. Physiol., 215, 1260-1275.

ELwYN D. H., I970. The role of the liver in regulation of aminoacid and protein metabolism, in MunRo H. N., ed. Mammalian protein metabolism. Vol. IV, 523-557. (Academic Press, New York, London).

Long C., r96I. In Long C., (ed). Biochemist's handboote, I123 (Spon, London I96I).

Lowry O. H., Rosebrough N. J., Farrand A. L., Randal, R. J., I951. Protein measurement with the Folinphenol reagent. J. Biol. Chem., 193, 265-275.

Munro H. N., ig66. In Thompson T. S. and Gillepsie I. E. Postgraduate gastroenterology, 58-66 (Baillere, London, I966).

Nasset E. S., Ju T. S, I96I. Mixture of endogenous and exogenous protein in the alimentary tract. J. Nutr., 74, 46I-465.

NixON S. E., MAWER G. F., r97o. The digestion and absorption of protein in man. II. The form in which digested protein is absorbed. $B r . J . N u t r ., 24,241-258$.

Rérat A., Lougnon J., 1966. Les besoins en aminoacides du porc en croissance. Cahier A.E.C., Commentry, 6, 341-422.

Snook J. T., r973. Protein digestion : Nutritional and metabolic considerations. World Rev. Nutr. Diet., 18, I 2 I-I 76.

Twombly J., Meyer J. H., I96r. Endogenous nitrogen secretions in to the digestive tract. J. Nutr., 74, $453-460$.

ZeBrowska T., BURACZEWSKA L., I972. Effect of amount of protein in the diet on amount and composition of the contents of the small intestine in pigs. Zesz. Probl. Postep. Nauk. Roln., 126, II5-I2I.

ZeBrowska T., 1973. Influence of dietary protein source on the rate of digestion in the small intestine of the pig. Part. I. Amount and composition of digesta. Rocz. Nauk. Roln. B. 95. I., II5-I33. 